\title{
Smad2 and Smad6 as predictors of overall survival in oral squamous cell carcinoma patients
}

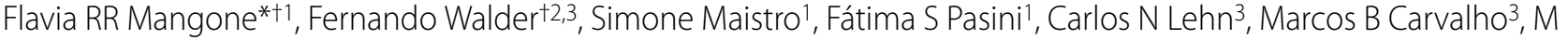 \\ Mitzi Brentani ${ }^{1}$ Igor Snitcovsky and Miriam HH Federico*1
}

\begin{abstract}
Background: To test if the expression of Smad1-8 mRNAs were predictive of survival in patients with oral squamous cell carcinoma (SCC).

Patients and Methods: We analyzed, prospectively, the expression of Smad1-8, by means of Ribonuclease Protection Assay in 48 primary, operable, oral SCC. In addition, 21 larynx, 10 oropharynx and 4 hypopharynx SCC and 65 matched adjacent mucosa, available for study, were also included. For survival analysis, patients were categorized as positive or negative for each Smad, according to median mRNA expression. We also performed real-time quantitative PCR (QRTPCR) to asses the pattern of TGF $\beta 1$, TGF $\beta 2$, TGF $\beta 3$ in oral SCC.

Results: Our results showed that Smad2 and Smad6 mRNA expression were both associated with survival in Oral SCC patients. Cox Multivariate analysis revealed that Smad6 positivity and Smad2 negativity were both predictive of good prognosis for oral SCC patients, independent of lymph nodal status ( $P=0.003$ and $P=0.029$, respectively). In addition, simultaneously Smad2- and Smad6 ${ }^{+}$oral SCC group of patients did not reach median overall survival (mOS) whereas the mOS of Smad2 $+/ S$ mad6 subgroup was 11.6 months ( $P=0.004$, univariate analysis). Regarding to TGF $\beta$ isoforms, we found that Smad2 mRNA and TGF $\beta 1$ mRNA were inversely correlated $(p=0.05, R=-0.33)$, and that seven of the eight TGF $\beta 1^{+}$patients were Smad2- In larynx SCC, Smad7- patients did not reach mOS whereas mOS of Smad7+ patients were only 7.0 months $(P=0.04)$. No other correlations were found among Smad expression, clinico-pathological characteristics and survival in oral, larynx, hypopharynx, oropharynx or the entire head and neck SCC population.

Conclusion: Smad6 together with Smad 2 may be prognostic factors, independent of nodal status in oral SCC after curative resection. The underlying mechanism which involves aberrant TGF $\beta$ signaling should be better clarified in the future.
\end{abstract}

\section{Background}

The Smad family of proteins, Smads 1 to 8 , are key molecules in Transforming Growth Factor- $\beta$ (TGF $\beta$ ) signaling, eventually modulating both TGF $\beta$ tumor suppressive and oncogenic effects [1]. Among them, Smad2 and Smad3 are known as receptor regulated Smads (R-Smads) and are phosphorylated in response to TGF $\beta$ itself. The phosphorylated protein, in conjunction with the common Smad (Co-Smad), Smad4, translocates to the nucleus eliciting the transcription of other genes [2-4]. The Inhibi-

\footnotetext{
* Correspondence: flavia@lim24.fm.usp.br, federico@usp.br

Disciplina de Oncologia, Departamento de Radiologia, LIM 24, Hospital das Clínicas da Faculdade de Medicina da Universidade de São Paulo, Avenida Dr Arnaldo 455, São Paulo, Brasil

+ Contributed equally

Full list of author information is available at the end of the article
}

tory Smads (I-Smads) Smad6 and 7, on the other hand, prevent the activation of R-Smad by phosphorylation and/or interfering with its nuclear translocation [5-7].

Smad signaling seems to be relevant to the pathogenesis of several epithelial cancers. Smad4 and Smad2 functions are disrupted in pancreatic, esophageal, gastric, colon and lung cancer [8-12]. Over-expression of inhibitory Smad6 and Smad7 was described in pancreatic cancer and in pancreatic cancer cell lines [13,14]. Smad2 and 3 present different targets and have distinctive roles, as shown in skin tumors of transgenic mice [15].

Concerning head and neck squamous cell carcinoma (HNSCC), however, data on Smads are still scarce. Studies done with HNSCC samples have shown alterations of individual Smad expression as measured by immunohis- 
tochemistry [16,17]. In addition, evidence obtained in in vitro studies indicates that Smad signaling may enhance invasiveness in HNSCC [18].

We have previously suggested that, in oral SCC but not in other HNSCC sites, the tumor supressive effect of TGF $\beta$ was absent in lymph node positive $(\mathrm{pN}+)$ but still present in lymph node negative (pN0) patients [19]. Therefore, we assumed that the extent of expression of individual Smad mRNAs might reflect the degree of TGF $\beta$ resistance, and in this way, correlate with progression in oral SCC and consequently with survival. In this work, we found that Smad family mRNA expression was globally increased in HNSCC as compared to adjacent tissue. In addition, among all Smads, Smad2 and Smad6 were suggested to be prognostic markers, correlating with overall survival.

\section{Patients and Methods Patients}

Surgical specimens of primary oral SCC were prospectively and sequentially obtained from 48 patients (median age 55 years, range 30 - 86; 43 male and 5 female) with previously untreated, operable HNSCC admitted at the Department of Head and Neck Surgery, Hospital Heliópolis - São Paulo - SP - Brazil. Matched adjacent mucosa, from the resection margin, was obtained from 40 patients. The Smad 1-8 mRNA expression of these and other 35 samples from different head and neck sites was evaluated. The general characteristics of patients are presented in Table 1.

All specimens were snap-frozen and stored in liquid nitrogen until analysis. Tumor staging was performed according to the Fifth Edition of the UICC TNM Classification of malignant tumors. Patient follow-up ranged from 14.0 to 53.0 months (median 33.0 months). At the last follow-up, among the 83 patients, 30 had local recurrences, 17 had regional recurrences, 44 patients had died and 6 patients were lost to follow-up.

The protocol was approved by the human review boards at the participating institutions and registered at Brazilian National Research Committee (CONEP). All patients provided voluntary written informed consent before enrolment in compliance with the Declaration of Helsinki and its amendments.

\section{RNA Extraction and Ribonuclease Protection Assay (RPA)}

Frozen tissue samples were pulverized and total RNA was obtained by using TRIzol Reagent (Invitrogen, Life Technologies) following the manufacturer's instructions. Detection and quantification of the Smad family members and of the ribosomal protein L32 were carried out with hSmad multiprobe template set (PharMingen's RiboQuant ${ }^{\text {mix }}$ Mult-Probe Ribonuclease Protection Assay System) according to the manufacturer's protocol. Briefly,
$10 \mu \mathrm{g}$ of total RNA were hybridized with $\alpha^{32}$ P-UTP (GE Healthcare Biosciences - formerly Amersham-Biosciences, St. Giles, UK) labelled riboprobes $\left(8.0 \times 10^{5} \mathrm{cpm}\right.$ per sample) for 16 hours at $56^{\circ} \mathrm{C}$, subjected to RNAse $\mathrm{A}+\mathrm{T} 1$ digestion followed by a phenol-chloroform extraction and ethanol precipitation. The protected double strand RNAs were eletrophoresed in a 5\% acrylamide/ bis-acrylamide (29:1) urea-containing gel, then the gel was dried and subjected to autoradiography (Hyperfilm, Amersham Biosciences) for 48 hs at $-70^{\circ} \mathrm{C}$. Specific bands were identified by their distinctive migration pattern as compared to the pattern of undigested probes. Densitometric analysis (ImageMaster VDS software, version 2.0 Amersham Biosciences) was used for quantification. Each Smad mRNA expression was normalized to L32 housekeeping gene.

\section{Real-Time Quantitative Reverse Transcriptase PCR (real time QRT PCR)}

Five micrograms of total RNA were reverse-transcribed using Random Hexamer primer pre-hit for 10 minutes at $70^{\circ} \mathrm{C}$ and incubated 10 minutes at room temperature before the addition of the reaction mix ( $1 \times$ Buffer Super Script III, $20 \mu \mathrm{M}$ of each deoxynucleotide triphosphate, 10 U Super Script III and 0.02 M DTT - Invitrogen, CA, USA). The reaction was performed at $55^{\circ} \mathrm{C}$ per $50 \mathrm{~min}$ utes and interrupted by 15 minutes incubation at $70^{\circ} \mathrm{C}$.

Real-time QRT PCR was carried out with SYBR Green dye in a Rotor Gene - RG300 (Corbett Research, DE). Oligonucleotide primers were designed for human TGF $\beta$ isoforms and $\beta$-actin house keeping using the Primer3 program (Whitehead Institute for Biomedical Research, http://www.bioinformatics.nl/cgi-bin/primer3/

primer3 www.cgi), based on its mRNA sequences. The synthesized forward and reverse primer sequences were (IDT, Integrated DNA Technologies, IA, USA): $\beta$-actin (NM_001101.3: fw 5'AGAAAATCTGGCACCACACC3' and rev 5'AGAGGCGTACAGGGATAGCA3'); TGF $\beta 1$ (NM_000660.4: fw 5'CCCTGGACACCAACTATTGC3' and rev 5'TGCGGAAGTCAATGTACAGC3'; TGF $\beta 2$ (NM_003238.2: fw 5'GAGTGCCTGAACAACGGATT3' and rev 5'TTCACAACTTTGCTGTCGATG3'); TGF 33 (NM_003239.2: fw 5'TGATCCAGGGGCTGGCGGAG3' and rev 5'GGGTTGGGCACCCGCAAGA3').

The PCR reaction mixture, performed with $100 \mathrm{ng}$ of cDNA, was: $1.5 \times$ SYBR Green I nucleic acid gel stain (Molecular Probes, OR, USA), $1 \times$ PCR Buffer, $2 \mathrm{mM}$ Magnesium Chloride, $0.2 \mathrm{mM}$ of each deoxynucleotide triphosphate, 1.5 U of Platinum Taq DNA Polymerase, 0.5 $\mathrm{mg} / \mathrm{mL}$ Bovine Serum Albumin Acetylated (Promega, WI, USA), $5 \%$ of DMSO (Sigma, CA, USA), $0.2 \mu \mathrm{M}$ of each primer in a total volume of $20 \mathrm{~mL}$ in Molecular Biology Grade Water (Invitrogen, Life Technologies, CA, USA). These experiments were performed in duplicate. 
Table 1: Clinical Pathological characteristics of studied population.

\begin{tabular}{|c|c|c|c|c|c|}
\hline & Oral Cavity & Larynx & Oropharynx & Hypopharynx & total \\
\hline \multicolumn{6}{|l|}{ Lymph node status } \\
\hline pNO & 23 & 11 & 2 & 2 & 38 \\
\hline pN+ & 25 & 10 & 8 & 2 & 45 \\
\hline \multicolumn{6}{|l|}{ Tumor size } \\
\hline pT1/T2 & 17 & 4 & 1 & 0 & 22 \\
\hline pT3/T4 & 31 & 17 & 9 & 4 & 61 \\
\hline \multicolumn{6}{|l|}{ Clinical Staging } \\
\hline $\mathrm{I} / \mathrm{II}$ & 13 & 4 & 0 & 0 & 17 \\
\hline III/IV & 35 & 17 & 10 & 4 & 66 \\
\hline total & 48 & 21 & 10 & 4 & 83 \\
\hline
\end{tabular}

Oral cavity: 25 mouth floor, 5 lower gum, 5 retromolar area, 10 tongue border, 1 hard palate, 1 tongue ventricular surface, 1 mouth anterior floor; Larynx: 6 aryepiglottic folds, 10 vocal cords, 3 epiglottis, 2 false cord; and Oropharynx: 2 glossotonsilar sulch, 6 tonsil, 1 soft palate, 1 vallecula. All 4 Hypopharynx tumors were from pyriform sinus.

The thermal cycling included an initial denaturation step of 5 minutes at $95^{\circ} \mathrm{C}$ followed by 35 cycles of 15 seconds at $95^{\circ} \mathrm{C}, 1$ minute at $60^{\circ} \mathrm{C}$ and 1 minute at $72^{\circ} \mathrm{C}$. Melting analysis was performed by heating the reaction mixture from 74 to $99^{\circ} \mathrm{C}$ at a rate of $0.2^{\circ} \mathrm{C} /$ second. Threshold cycle (Ct) and melting curves were acquired by using the "quantitation" and "melting curve" program of the Rotor gene 6 software version 6.0 Corbett Research (Corbett Research, DE). Only genes with clear and single melting peaks were taken for further data analysis. Samples with irregular melting peaks were excluded from the calculation. The threshold was set manually, using identical threshold levels for one gene in all analyzed samples. Reaction efficiency was established for each set of primers, after quantification of four different dilutions of a reference cDNA.

The Ct value of three targets genes (TGF $\beta 1$, TGF $\beta 2$ and TGF 33 ) was normalized to the reference gene $\mathrm{Ct}$ ( $\beta$ actin) and the relative quantification was performed according to Pfaff mathematical model [20].

\section{Statistical analysis}

Comparisons between groups were performed by the paired Wilcoxon test, when appropriate. For survival and Spearman's correlation analysis, patients were categorized as positive $\left(\mathrm{Smad}^{+}, \mathrm{TGF} \beta^{+}\right)$or negative $\left(\mathrm{Smad}^{-}\right.$, TGF $\beta^{-}$) according to the median relative expression of each (above or equal/below the correspondent median tumor expression). Overall survival (OS) and disease free survival (DFS) were considered from the day of the surgery to date of death or the date in which recurrence was detected, by means of physical examination or imaging. Survival curves were estimated using the Kaplan Meier method and compared using the univariate Log Rank test. A Cox multivariate analysis was performed to identify independent predictors of survival. All statistics were done using SPSS 10.0 statistical software (SPSS Inc., Chicago, IL). Differences were considered statistically significant for $P$ value $\leq 0.05$.

\section{Results}

\section{Smad mRNA expression in oral SCC}

In this study, we determined Smads (Smad1 to 8) mRNA expression in 48 primary tumors (Table 1) from patients with oral SCC submitted to curative ressection (see representative assay in figure 1A). Quantification of the RPA signals, normalized to L32 mRNA, revealed that, up to $91 \%$ of the tumors expressed all Smad mRNAs, except for Smad8 mRNA, detected in $73 \%$ of the tumors. In parallel, $100 \%$ of the 40 available specimens of adjacent mucosa expressed Smads 1 to 7, and Smad8 mRNA expression was detected in $52.5 \%$. The distribution and median of Smads expression are shown in Figure 1B.

Paired analysis revealed that oral SCC express more Smad2, 3, 5 and 7 mRNAs than matched mucosas $(P<$ 0.05 , Table 2). When clinical-pathological features such as lymph node status, tumor size, differentiation degree, pathological staging, age, gender and smoking degree were considered, no statistically significant differences were found.

In survival analysis, Smad2- patients presented longer median OS as compared to Smad2+ patients (median OS 


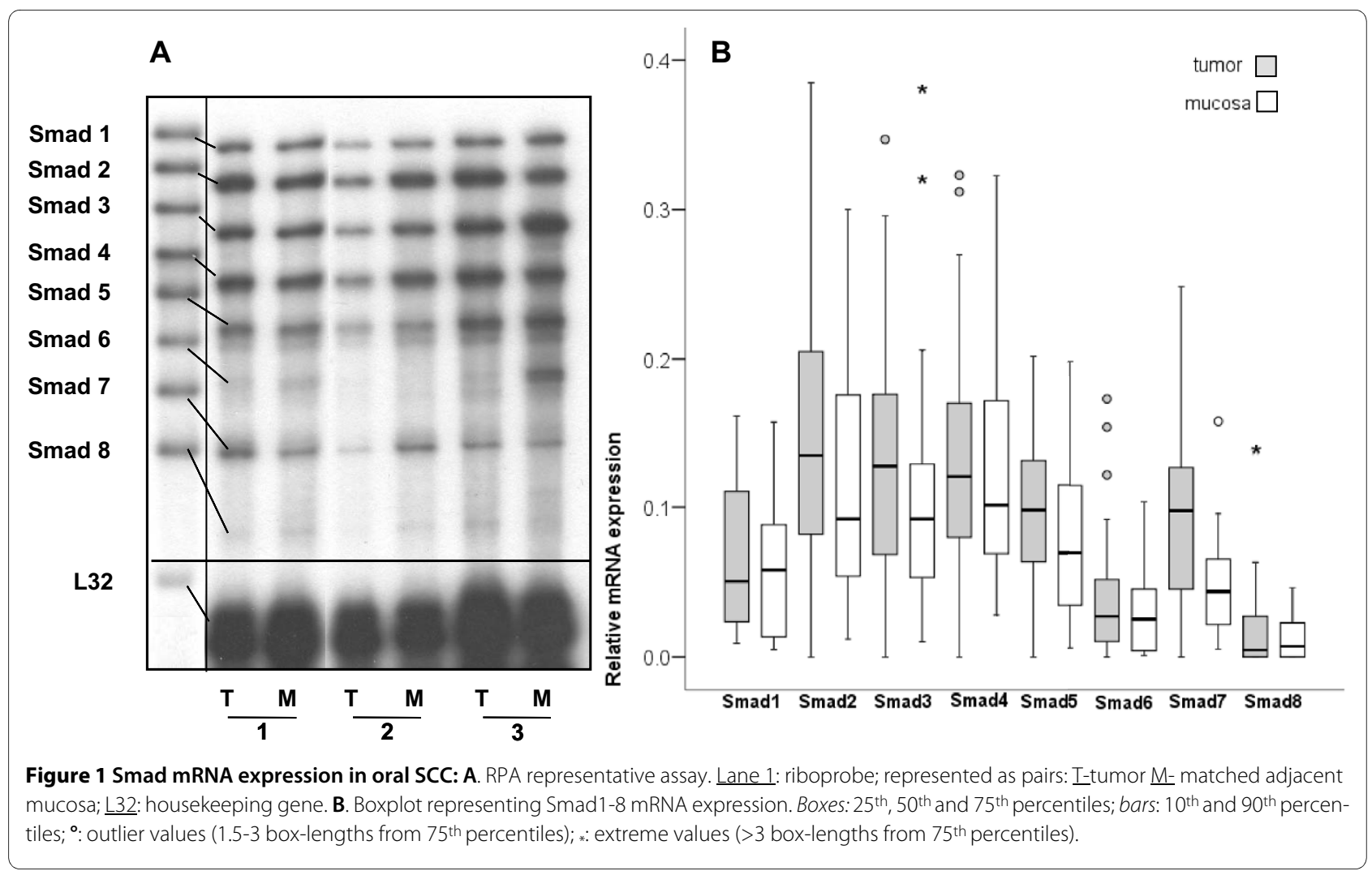

not reached and 14.6 months, respectively), while the mOS for the entire oral SCC group was 31 months, a similar behaviour being found for mDFS (Figure 2A and 2B). Similarly, Smad6 ${ }^{+}$patients presented a median OS three times longer than Smad6- patients (52 and 14.6 months, respectively). Also, the Smad6 ${ }^{+}$mDFS was 52 months, six times longer than that of Smad6- patients (Figure 2C and 2D). According to lymph node status, the mOS was 37 months in pN0 patients and 14 months in $\mathrm{pN}+$ patients, with survival rates of $61 \%$ in pN0 patients $(n=23)$ and 36 in $\mathrm{pN}+$ patients $(\mathrm{n}=25, \mathrm{p}<0.05)$.

By Cox regression multivariate analysis, those two markers, Smad2 and Smad6, were shown to be prognostic factors in oral SCC, independent of lymph nodal status (Table 3). In line with this, even with a small population, $\mathrm{pN}+$ patients who were Smad6 ${ }^{+}$presented 31 months mOS, three times longer than that presented by Smad6patients (11 months). Accordingly, in the pN0 subgroup, Smad6- patients had 23 month mOS, shorter than that of $\mathrm{Smad6}^{+}$patients who did not reach $\mathrm{mOS}(P=0.009)$. The same seems to occur with simultaneously Smad2+ and $\mathrm{pN}+$ patients who presented a poorer prognosis as compared to Smad2 $/ \mathrm{pN}+$ patients who did not reach mOS. Consonant with this, patients who were Smad2-/Smad6+ simultaneously did not reach mOS and mDFS whereas Smad2+/Smad6- patients presented mOS 12 months and
mDFS 6 months $(P=0.0044, P=0.0012$, respectively, Figure $2 \mathrm{E}, \mathrm{F})$.

\section{Smad mRNA expression in larynx SCC and in other HNSCC subsites}

Except for Smad6 (90\%) and Smad8 (86\%), Smads were expressed in $100 \%$ of larynx SCC. In matched adjacent mucosa, Smad6 was expressed in $73 \%$, Smad7 in $93 \%$ and Smad8 in $67 \%$, the others being expressed in $100 \%$ of samples.

Paired analysis revealed that only $\mathrm{Smad} 7$ was overexpressed in tumors $(0.08 \pm 0.06)$ as compared to adjacent mucosa $(0.03 \pm 0.04, P=0.002)$. This marker was the only one to correlate with survival in this subset of patients, with a survival advantage observed in Smad7- patients (mOS not reached) over those who were Smad7 ${ }^{+}$(mOS 6.97 months, $P=0.04$, Figure 3 ). The survival rate of Smad7 ${ }^{-}$and Smad7 ${ }^{+}$patients was $54.5 \%$ and $30 \%$ respectively. When clinical-pathological features as lymph node status, tumor size, differentiation degree, pathological staging, age, gender and smoking degree were considered, no statistical difference was found related to Smad7 status.

In oropharynx SCC, even with a small sample size, paired analysis showed Smad overexpression for Smad2 to 5 , while in the entire HNSCC population, a significant difference was not achieved only for Smad8, confirming 
Table 2: Smad mRNA expression in head and neck SCC and adjacent mucosa.

\begin{tabular}{|c|c|c|c|c|c|}
\hline & & All patients $n=65$ & Oral Cavity $n=40$ & Larynx $n=15$ & Oropharynx $n=8$ \\
\hline \multirow[t]{3}{*}{ Smad1 } & $\mathbf{T}$ & $0.06 \pm 0.06$ & $0.06 \pm 0.05$ & $0.07 \pm 0.06$ & $0.06 \pm 0.10$ \\
\hline & $M$ & $0.05 \pm 0.05$ & $0.06 \pm 0.05$ & $0.05 \pm 0.04$ & $0.03 \pm 0.05$ \\
\hline & & $P=0.017^{*}$ & $P=0.209$ & $P=0.256$ & $P=0.012$ \\
\hline \multirow[t]{3}{*}{ Smad2 } & $\mathbf{T}$ & $0.15 \pm 0.10$ & $0.16 \pm 0.10$ & $0.17 \pm 0.10$ & $0.13 \pm 0.10$ \\
\hline & $M$ & $0.11 \pm 0.09$ & $0.11 \pm 0.08$ & $0.15 \pm 0.10$ & $0.08 \pm 0.11$ \\
\hline & & $P=0.002^{*}$ & $P=0.020^{*}$ & $P=0.532$ & $P=0.036^{*}$ \\
\hline \multirow[t]{3}{*}{ Smad3 } & $\mathbf{T}$ & $0.15 \pm 0.11$ & $0.13 \pm 0.08$ & $0.18 \pm 0.13$ & $0.18 \pm 0.16$ \\
\hline & $M$ & $0.11 \pm 0.09$ & $0.10 \pm 0.08$ & $0.15 \pm 0.12$ & $0.06 \pm 0.08$ \\
\hline & & $P=0.001^{*}$ & $P=0.028^{*}$ & $P=0.047^{*}$ & $P=0.017^{*}$ \\
\hline \multirow[t]{3}{*}{ Smad4 } & $\mathbf{T}$ & $0.13 \pm 0.09$ & $0.13 \pm 0.08$ & $0.15 \pm 0.09$ & $0.12 \pm 0.12$ \\
\hline & M & $0.11 \pm 0.08$ & $0.12 \pm 0.07$ & $0.13 \pm 0.08$ & $0.09 \pm 0.11$ \\
\hline & & $P=0.051^{*}$ & $P=0.202$ & $P=0.733$ & $P=0.017^{*}$ \\
\hline \multirow[t]{3}{*}{ Smad5 } & $\mathbf{T}$ & $0.10 \pm 0.06$ & $0.10 \pm 0.05$ & $0.12 \pm 0.08$ & $0.08 \pm 0.07$ \\
\hline & $M$ & $0.08 \pm 0.06$ & $0.08 \pm 0.05$ & $0.01 \pm 0.07$ & $0.04 \pm 0.06$ \\
\hline & & $P=0.001^{*}$ & $P=0.006^{*}$ & $P=0.798$ & $P=0.036^{*}$ \\
\hline \multirow[t]{3}{*}{ Smad6 } & $\mathbf{T}$ & $0.03 \pm 0.04$ & $0.04 \pm 0.04$ & $0.03 \pm 0.03$ & $0.01 \pm 0.01$ \\
\hline & $M$ & $0.02 \pm 0.02$ & $0.03 \pm 0.03$ & $0.10 \pm 0.01$ & $0.01 \pm 0.02$ \\
\hline & & $P=0.072^{*}$ & $P=0.132$ & $P=0.334$ & $P=0.833$ \\
\hline \multirow[t]{3}{*}{ Smad7 } & $\mathbf{T}$ & $0.08 \pm 0.06$ & $0.09 \pm 0.06$ & $0.08 \pm 0.06$ & $0.04 \pm 0.03$ \\
\hline & $M$ & $0.04 \pm 0.03$ & $0.05 \pm 0.03$ & $0.03 \pm 0.04$ & $0.03 \pm 0.03$ \\
\hline & & $P<0.0001^{*}$ & $P<0.0001^{*}$ & $P=0.002^{*}$ & $P=0.123$ \\
\hline \multirow[t]{3}{*}{ Smad8 } & $\mathbf{T}$ & $0.02 \pm 0.03$ & $0.02 \pm 0.03$ & $0.02 \pm 0.03$ & $0.01 \pm 0.01$ \\
\hline & $M$ & $0.01 \pm 0.02$ & $0.01 \pm 0.01$ & $0.02 \pm 0.03$ & $0.01 \pm 0.01$ \\
\hline & & $P=0.378$ & $P=0.389$ & $P=0.875$ & $P=0.496$ \\
\hline
\end{tabular}

T: tumor, $\mathbf{M}$ : adjacent mucosa. Values are presented as median \pm standard deviation, ${ }^{*}$ significant differences by Wilcoxon test.

that differences between HNSCC subsites must be considered (Table 2).

Concerning Smad expression, OS and DFS, no correlations were found as revealed by Log Rank analysis, in the HNSCC population as a whole.

\section{TGF $\beta$ isoforms mRNA expression profile in Oral SCC}

We assessed the three TGF $\beta$ isoforms using real-time QRT PCR in 35 available oral SCC. TGF $\beta 1$ mRNA expression was observed in $100 \%$ of samples (mean \pm standard deviation: $0.82 \pm 0.68$, median: 0.57), while TGF 32 (94\%) and TGF 33 (97\%) isoforms were detected in almost all tumors (TGF $\beta 2: 1.24 \pm 1.82,0.72$; TGF $\beta 3$ : $2.12 \pm 3.58,1.15)$.

No statistically significant associations were found between TGF $\beta$ isoforms and clinical-pathological characteristics such as $\mathrm{pT}, \mathrm{pN}$, pathological staging and histological differentiation. After categorization according to median mRNA expression, the observed positivity of each isoform was $23 \%, 37 \% 49 \%$ for TGF $\beta 1$, TGF $\beta 2$ and TGF $\beta 3$, respectively.

The correlations among categorized Smad2, Smad6, TGF $\beta 1$, TGF $\beta 2$ and TGF $\beta 3$ were tested by Spearman's 

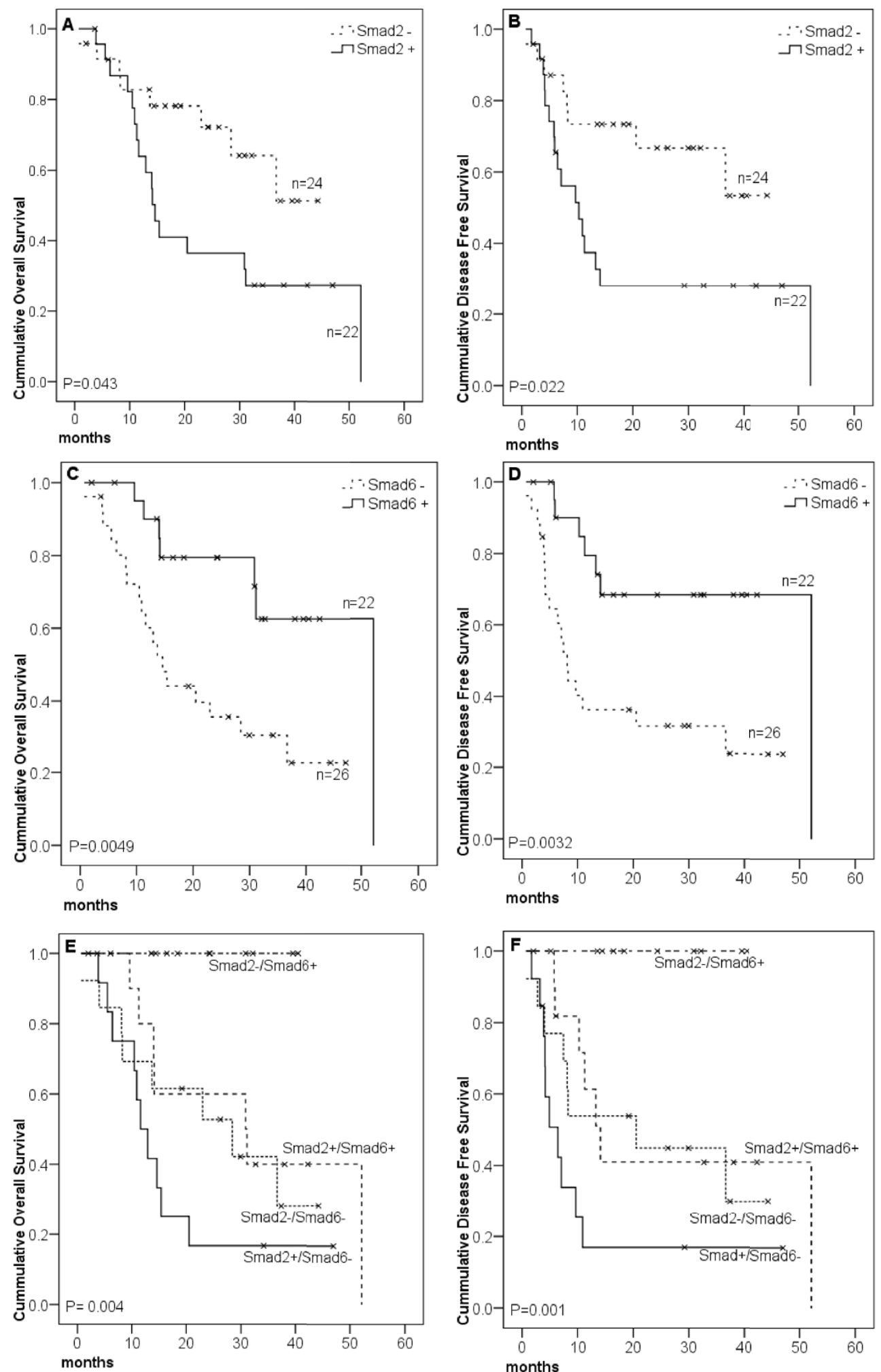

Figure 2 Kaplan-Meier survival curves of oral cavity SCC patients grouped according to Smad expression. Patients were categorized as positive (above) or negative (equal or below) according to median Smad expression in tumors. Log Rank test was performed for curves comparison. In $\mathbf{E}$ and $\mathbf{F}$, patients were grouped according to the co-expression of Smad2 and Smad6. Smad2 $+/ \mathrm{Smad}^{-}: \mathrm{n}=13 ; \mathrm{Smad}^{+} / \mathrm{Smad} 6^{+}: \mathrm{n}=11 ; \mathrm{Smad}^{-2} / \mathrm{Smad}^{-}$ $: \mathrm{n}=13 ; \mathrm{Smad}_{2}-\mathrm{Smad6}^{+}: \mathrm{n}=11$. 
Table 3: Cox multivariate analyses of survival prediction in oral SCC.

\begin{tabular}{lcc}
\hline Variable & Hazard ratio (95\% Cl) & P value \\
\hline Smad2 & $0.374(0.155-0.906)$ & 0.029 \\
Smad6 & $4.153(1.613-10.692)$ & 0.003 \\
pN & $0.598(0.233-1.531)$ & 0.284 \\
PT & $0.557(0.197-1.575)$ & 0.270 \\
\hline
\end{tabular}

$\mathrm{Cl}$ - confidence interval

rho test. Results revealed that Smad2 was inversely correlated to TGF $\beta 1(P=0.05, \mathrm{R}=-0.33)$. Among the eight TGF $\beta 1^{+}$tumors, seven (87.5\%) were also Smad2-, while in TGF $\beta 1^{-}$subgroup an equal distribution between Smad2(48\%) and Smad2+ (52\%) was observed.

\section{Discussion}

In this study, we provide evidence that Smads may have a key role in head and neck cancer, influencing survival. Specifically, we show, prospectively, that high Smad6 mRNA expression and low Smad2 mRNA correlate with better survival in oral SCC patients submitted to curative surgery, independent of nodal status. In addition, Smad7 high mRNA expression correlated with shorter survival in patients with larynx SCC submitted to curative surgery. The fact that these correlations were restricted to specific tumor locations supports the hypothesis that

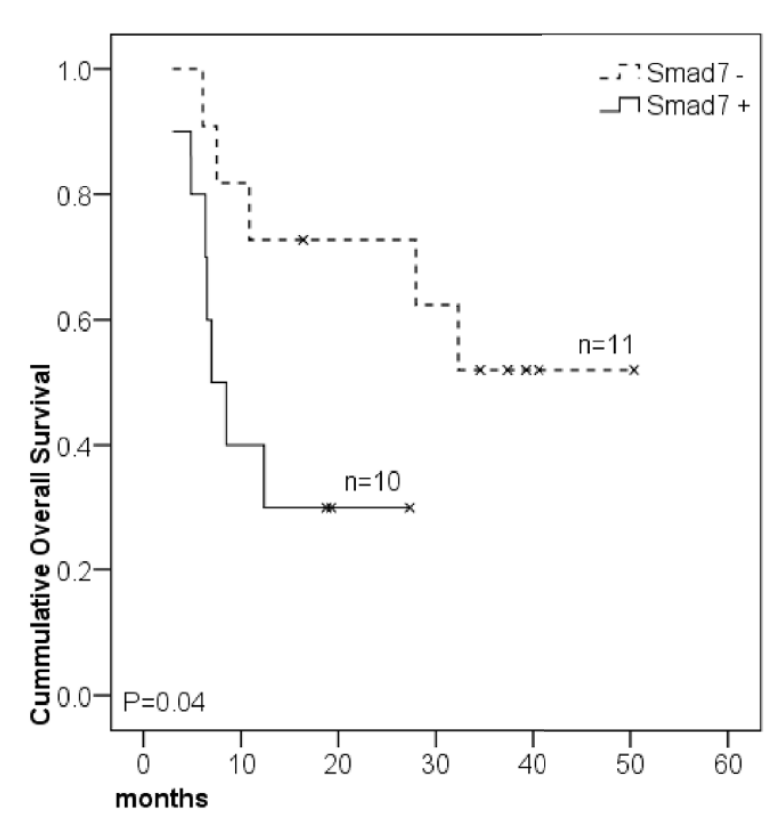

Figure 3 Kaplan-Meier survival curves of larynx SCC patients grouped according to Smad expression. Patients were categorized as positive (above) or negative (equal or bellow) according to median tumor expression. Log Rank test was performed for curves comparison. underlying biological heterogeneity exists between different subsites within head and neck.

TGF $\beta$ is known as a potent tumor supressor in normal epithelial cells and in early-stage tumors but during tumor progression it becomes an oncogenic factor, mainly in advanced tumors [21]. Since Smad6 has a blocking effect on TGF $\beta$ signaling either by direct binding to the TGF $\beta$ receptor, by competing with Co-Smad for R-Smad complex formation or by targeting receptor for degradation $[6,7,22,23]$, we can speculate that this effect on survival occurs because Smad6 would inhibit the TGF $\beta$ tumorigenic signaling, thus favouring a better outcome. The favorable prognosis presented by Smad6 ${ }^{+}$ oral SCC patients agrees with that described in 115 esophageal SCC using immunohistochemistry [24]. Reinforcing this idea, we found that even in the poor prognosis group, $\mathrm{pN}+$, the presence of $\mathrm{Smad6}^{+}$was associated with a survival advantage similar to that of pN0 patients.

Smad2 is the classically R-Smad of the TGF $\beta$ pathway [1], our own data suggest Smad2 negativity reinforces the effect of Smad6 on survival of oral SCC. Smad2 may be a key factor for the interruption of TGF $\beta$ tumorigenic signaling in this group of patients, together with Smad6. In accordance with that, we found TGF $\beta 1$ positive tumors were also Smad2 negative. Our finding regarding the association between lack of Smad2 expression and a favourable clinical outcome is in disagreement with previous studies done in head and neck cancer as well as other tumor types. In oral squamous cell carcinoma, a study involving 125 patients suggested a link between decreased expression of both activated Smad2 (p-Smad2) and TGF $\beta$ receptor II (T $\beta R-I I)$, with aggressive tumor features, which suggests TGF $\beta$ signaling exerts a protective role possibly through Smad 2 [25]. In accordance, the Smad expression profile assessed by tissue array in 170 head and neck squamous cell carcinoma pointed to the loss of $\mathrm{TGF} \beta / \mathrm{Smad} 2$ signaling as a possible cause of adverse outcome [17]. A protective role of Smad 2 was also suggested for esophageal, colon and breast cancer [26-28]. In line with this effect, others have identified a missense mutation of $\mathrm{Smad} 2$ in the squamous cell line SCC-15 suggesting that the loss of Smad 2 may be part of head and neck carcinogenesis [29]. 
There are, however, several studies in line with our data. Matrix metalloproteinases play roles in cancer progression by degrading the extracellular matrix and basement membrane. TGF $\beta 1$ signaling induces MMP-9 expression via Smad 2/3 [30]. Accordingly, the TGF $\beta 1 /$ Smad 2/3 axis regulates MMP-9 expression through the transcriptional factors Snail and Ets-1, contributing to oral cancer progression [31]. In addition, the metastasisassociated protein metastatin can physically and functionally interact with $\mathrm{Smad} 2 / 3$, and enhance TGF $\beta$ mediated MMP-9 induction [32]. Activation of Smad 2/3 signaling has also been linked to enhancement of MMP13 expression and invasion of head and neck squamous carcinoma cells [18].

Smad 2 accumulation seems to parallel an elevation of $\mathrm{H}$-ras, both of which are essential for epithelial mesenchymal transition (EMT), an essential step during carcinogenesis. Having undergone EMT, others have shown that fibroblastoid carcinoma cells with elevated levels of activated Smad2 gain the capability to spread to a wide variety of tissues by a further increase in Smad2 expression [33]. In addition, a prominent expression of alpha(v)beta(6) integrin at tumor stroma interface in xenograft model, which resembles human head and neck carcinomas, has been connected with cancer progression. Alpha(v)beta(6) interacts with TGF 3 , as an Alpha(v)beta(6) blocking antibody can inhibit TGF $\beta$ mediated Smad2/3 phosphorylation, which leads to inhibition of tumor growth in vivo, suggesting a role for the microenvironment for this effect [34].

It is not easy to reconcile these conflicting results regarding the role of Smad2, in head and neck tumors, since they reflect the dual roles of TGF $\beta$ itself, acting both as a tumor suppressor and a tumor enhancer, depending on the context. What is not clear, however, is what constitutes this context [35]. In our head and neck patient series, Smad2 seems to be a TGF $\beta$ signaling node that enhances tumor aggressiveness (Figure 4). An intriguing possibility, that merits further study, is that HPV infection may be interacting with TGF $\beta$ network as shown in cervical carcinoma [36].

Taking into account that Smad6 is at the crossroad of many signaling pathways, being regulated not only by family members of bone morphogenetic protein (BMP) and TGF $\beta$, but also by epidermal growth factor and Ras/ MAPK $[6,7,37]$, its expression may be key to shift signaling from oncogenesis to tumor supression, towards or against proliferation, independent of Smad3 and Smad4, at least in oral SCC (Figure 4).

If we consider Smad6 and Smad7 as interchangeable TGF $\beta$ blocking Smads, our data in oral SCC is also in keeping with others, showing that a combination of increased immunohistochemical expression of Smad7 and decreased Smad4 expression are markers of good

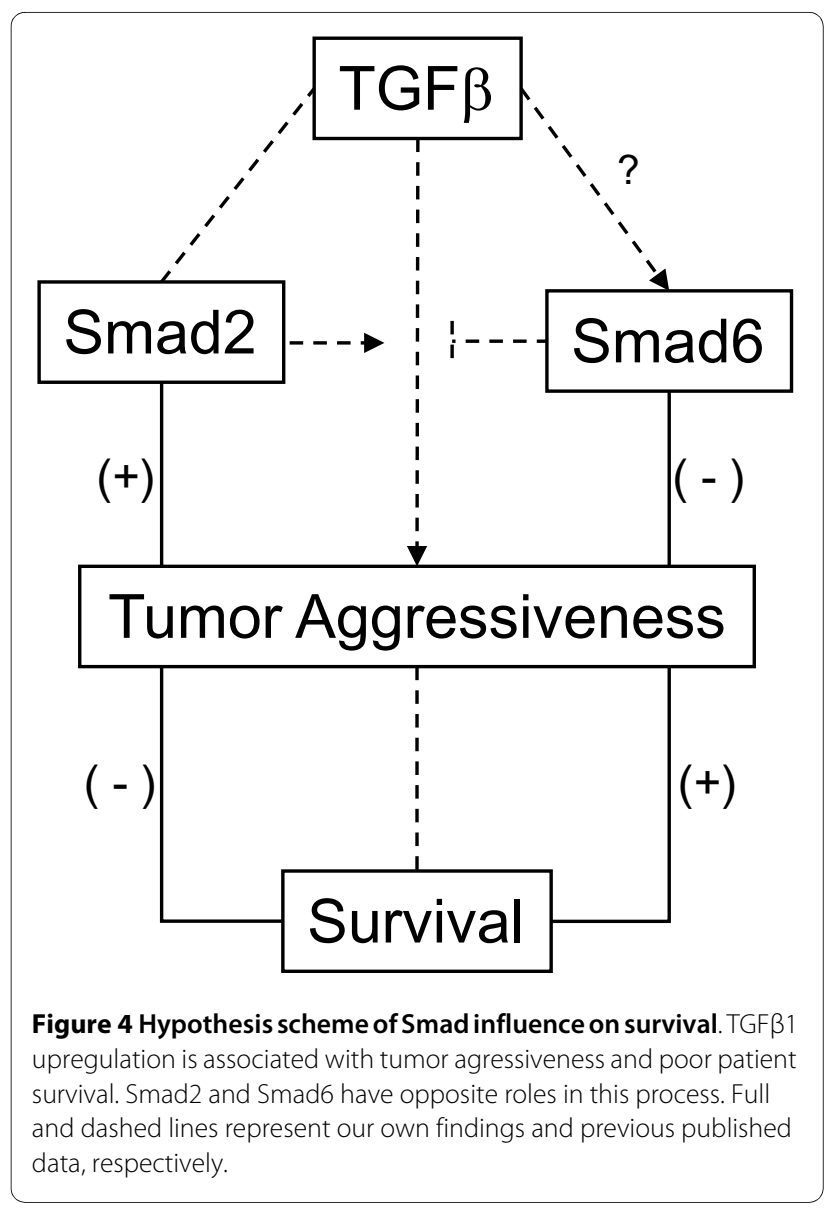

prognosis in gastric cancer, with $67.5 \%$ survival rate versus $52.2 \%$, $(P=0.0011)$ [38]. However, data concerning Smad7 seems to be more controversial since our own present data indicates that Smad7 mRNA low expression correlates with shorter survival in larynx SCC (Figure 3). In agreement with our results, patients with colon and gastric cancers, with Smad7 gene deletion or low Smad7 protein expression, were described as having prolonged survival as compared to patients with higher Smad7 expression $[39,38]$.

Concerning the lack of influence of Smad4 mRNA expression on patient survival in our study, data in the literature suggests that there is no single rule for this. Low Smad4 expression, detected by immunohistochemistry, and poorer five-year survival was shown in 249 patients with advanced gastric cancer and in 258 esophageal squamous cell carcinomas $(P<0.05)[9,10]$. In colon cancer, such an influence was not shown, which is in accordance with our present data [39]. Taking into account that Smad4 mRNA was the most ubiquitous among Smads we can argue that perhaps the amount of Smad4 was not a crucial element for these patients.

Finally, we found higher Smad mRNA expression in SCC primary tumors as compared to adjacent tissue in 
agreement with previously published data, showing that HNSCC cell lines present multiple defects in TGF-beta signaling [40]. In HNSCC samples, data obtained from 170 tumors using tissue array technology, shows expression of Smad2, Smad3 and Smad4 proteins [17]. Another small study comparing the expression between tumor and adjacent tissue did not find differences at least with respect to Smad4, Smad6 and Smad7 protein expression in 13 head and neck SCC tumors [16].

To sum up, our results suggest that increased Smad6 mRNA expression and low Smad2 mRNA expression might be markers of better outcome in oral SCC but not in larynx cancer submitted to curative surgery. These effects may be linked to aberrant TGF $\beta$ signalling. In larynx cancer, a similar relationship was found for Smad7 mRNA low expression. Our findings need to be validated in larger prospective studies, and may in the future, help to stratify candidate patients for adjuvant treatment in head and neck cancer.

\section{Conclusions}

TGF $\beta$ is classically known as tumor supressor in normal epithelial cells that turns into a malignant factor during tumor progression favoring tumor growth and metastasis. Here we propose that the interruption in TGF $\beta$ tumorigenicity by Smad2 dowregulation or by Smad6 overexpression confers a better outcome. Although both might be considered as prognostic markers, the molecular mechanism envolved in this process is not clear. Further studies are warranted to explore the mechanisms involved.

\section{Competing interests}

The authors declare that they have no competing interests.

\begin{abstract}
Authors' contributions
FRRM carried out RNAse protection assay and Real-Time QRTPCR, was involved in the study design, data management, statistical analysis and manuscript preparation, FSP responsible for primer designing, real-time QRTPCR support, helped in statistical analysis and revised the manuscript SM helped in statistical analysis and revised the manuscript; SI oversaw the statistical analysis and helped draft the manuscript; $C L, F W$ and $M B C$ were the head and neck surgeons in the team, who collected samples, all clinical data and were involved with data management; MMB helped to draft the manuscript; MHHF conceived and was responsible for coordination of the study, and was responsible for the study funding through FAPESP. All authors read and approved the final manuscript
\end{abstract}

\section{Acknowledgements}

This study was supported by FAPESP 02/01738-9 and CNPq

\section{Author Details}

1Disciplina de Oncologia, Departamento de Radiologia, LIM 24, Hospital das Clínicas da Faculdade de Medicina da Universidade de São Paulo, Avenida Dr Arnaldo 455, São Paulo, Brasil, ²Departamento de Otorrinolaringologia, Universidade Federal de São Paulo, São Paulo, Brasil and ${ }^{3}$ Serviço de Cirurgia de Cabeça e Pescoço, Hospital Heliópolis, São Paulo, Brasil

Received: 8 May 2009 Accepted: 12 May 2010

Published: 12 May 2010
References

1. Schmierer B, Hill CS: TGFbeta-SMAD signal transduction: molecular specificity and functional flexibility. Nat Rev Mol Cell Biol 2007, 8:970-982.

2. Feng $X H$, Derynck R: Specificity and versatility in tgf-beta signaling through Smads. Annu Rev Cell Dev Biol 2005, 21:659-693.

3. Liu IM, Schilling SH, Knouse KA, Choy L, Derynck R, Wang XF: TGFbetastimulated Smad1/5 phosphorylation requires the ALK5 L45 loop and mediates the pro-migratory TGFbeta switch. EMBO J 2009, 28:88-98.

4. Xu L: Regulation of Smad activities. Biochim Biophys Acta 2006, 1759:503-513

5. Miyazono K, Suzuki H, Imamura T: Regulation of TGF-beta signaling and its roles in progression of tumors. Cancer Sci 2003, 94:230-234

6. Afrakhte M, Morén A, Jossan S, Itoh S, Sampath K, Westermark B, Heldin $\mathrm{CH}$, Heldin NE, ten Dijke P: Induction of inhibitory Smad6 and Smad7 mRNA by TGF-beta family members. Biochem Biophys Res Commun 1998, 249:505-511.

7. Takase M, Imamura T, Sampath TK, Takeda K, Ichijo H, Miyazono K, Kawabata M: Induction of Smad6 mRNA by bone morphogenetic proteins. Biochem Biophys Res Commun 1998, 244:26-9.

8. Chiao PJ, Hunt KK, Grau AM, Abramian A, Fleming J, Zhang W, Breslin T, Abbruzzese JL, Evans DB: Tumor suppressor gene Smad4/DPC4, its downstream target genes, and regulation of cell cycle. Ann N Y Acad Sci 1999, 880:31-7.

9. Natsugoe $S$, Xiangming C, Matsumoto M, Okumura H, Nakashima S, Sakita H, Ishigami S, Baba M, Takao S, Aikou T: Smad4 and transforming growth factor beta1 expression in patients with squamous cell carcinoma of the esophagus. Clin Cancer Res 2002, 8:1838-1842.

10. Xiangming C, Natsugoe S, Takao S, Hokita S, Ishigami S, Tanabe G, Baba M, Kuroshima K, Aikou T: Preserved Smad4 expression in the transforming growth factor beta signaling pathway is a favorable prognostic factor in patients with advanced gastric cancer. Clin Cancer Res 2001, 7:277-282.

11. Takagi Y, Kohmura H, Futamura M, Kida H, Tanemura H, Shimokawa K, Saji S: Somatic alterations of the DPC4 gene in human colorectal cancers in vivo. Gastroenterology 1996, 111:1369-1372.

12. Nagatake M, Takagi Y, Osada H, Uchida K, Mitsudomi T, Saji S, Shimokata K, Takahashi T, Takahashi T: Somatic in vivo alterations of the DPC4 gene at $18 q 21$ in human lung cancers. Cancer Res 1996, 56:2718-2720.

13. Kleeff J, Ishiwata T, Maruyama H, Friess H, Truong P, Büchler MW, Falb D, Korc M: The TGF-beta signaling inhibitor Smad7 enhances tumorigenicity in pancreatic cancer. Oncogene 1999, 18:5363-5372.

14. Kleeff J, Maruyama H, Friess H, Büchler MW, Falb D, Korc M: Smad6 suppresses TGF-beta-induced growth inhibition in COLO-357 pancreatic cancer cells and is overexpressed in pancreatic cancer. Biochem Biophys Res Commun 1999, 255:268-273.

15. Tannehill-Gregg SH, Kusewitt DF, Rosol TJ, Weinstein M: The role of Smad 2 and Smad3 in the development of chemically induced skin tumors in mice. Vet Pathol 2004, 41:278-282.

16. Muro-Cacho CA, Rosario-Ortiz K, Livingston S, Muñoz-Antonia T: Defective transforming growth factor beta signaling pathway in head and neck squamous cell carcinoma as evidenced by the lack of expression of activated Smad2. Clin Cancer Res 2001, 7:1618-1626.

17. Xie W, Bharathy S, Kim D, Haffty BG, Rimm DL, Reiss M: Frequent alterations of Smad signaling in human head and neck squamous cell carcinomas: a tissue microarray analysis. Oncol Res 2003, 14:61-73.

18. Leivonen SK, Ala-Aho R, Koli K, Grénman R, Peltonen J, Kähäri VM: Activation of Smad signaling enhances collagenase -3 expression and invasion of head and neck carcinoma cells. Oncogene 2006, 27:2588-2600.

19. Pasini FS, Brentani MM, Kowalski LP, Federico MH: Transforming growth factor beta1, urokinase-type plasminogen activator and plasminogen activator inhibitor-1 mRNA expression in head and neck squamous carcinoma and normal adjacent mucosa. Head Neck 2001, 23:725-732.

20. Pfaffl MW: A new mathematical model for relative quantification in realtime RT-PCR. Nucleic Acids Res 2001, 29:e45.

21. Lönn P, Morén A, Raja E, Dahl M, Moustakas A: Regulating the stability of TGF $\beta$ receptors and Smads. Cell Research 2009, 29:21-35.

22. Imamura T, Takase M, Nishihara A, Oeda E, Hanai J, Kawabata M, Miyazono K: Smad6 inhibits signalling by the TGF-beta superfamily. Nature 1997, 389:622-626. 
23. Lönn P, Morén A, Raja E, Dahl M, Moustakas A: Regulating the stability of TGFbeta receptors and Smads. Cell Res 2009, 19:21-35.

24. Osawa H, Nakajima M, Kato H, Fukuchi M, Kuwano H: Prognostic value of the expression of Smad6 and Smad7, as inhibitory Smads of the TGFbeta superfamily, in esophageal squamous cell carcinoma. Anticancer Res 2004, 24:3703-3709.

25. Peng H, Shintani S, Kim Y, Wong DT: Loss of p12 cd2-ap1 expression in human oral squamous cell carcinoma with disrupted trasnforming growth factor $\beta$-Smad signaling patway. Neoplasia 2006, 6:1028-1036.

26. Fukuchi M, Nakajima M, Miyazaki T, Masuda N, Osawa H, Manda R, Tsukada K, Kato H, Kuwano H: Lack of activated Smad2 in transforming growth factor-beta signaling is an unfavorable prognostic factor in patients with esophageal squamous cell carcinoma. J Surg Oncol 2006, 94:51-6.

27. Xie W, Mertens JC, Reiss DJ, Rimm DL, Camp RL, Haffty BG, Reiss M: Alterations of Smad signaling in human breast carcinoma are associated with poor outcome: a tissue microarray study. Cancer Res 2002, 62:497-505.

28. Koumoundourou D, Kassimatis T, Zolota V, Tzorakoeleftherakis E, Ravazoula P, Vassiliou V, Kardamakis D, Varakis J: Prognostic significance of TGFbeta- 1 and pSmad2/3 in breast cancer patients with T1-2, N0 tumours. Anticancer Res 2007, 27:2613-2620.

29. Qiu W, Schönleben F, Li X, Su GH: Disruption of transforming growth factor beta-Smad signaling pathway in head and neck squamous cell carcinoma as evidenced by mutations of SMAD2 and SMAD4. Cancer Lett 2007, 245:163-170.

30. Sinpitaksakul SN, Pimkhaokham A, Sanchavanakit N, Pavasant P: TGFbeta1 induced MMP-9 expression in HNSCC cell lines via Smad/MLCK pathway. Biochem Biophys Res Commun 2008, 371:713-718.

31. Sun L, Diamond ME, Ottaviano AJ, Joseph MJ, Ananthanarayan V, Munshi HG: Transforming growth factor-beta 1 promotes matrix metalloproteinase-9-mediated oral cancer invasion through snail expression. Mol Cancer Res 2008, 6:10-20.

32. Matsuura I, Lai CY, Chiang KN: Functional interaction between Smad3 and S100A4 (metastatin-1) for TGF-beta-mediated cancer cell invasiveness. Biochem J 2010, 426:327-35.

33. Oft M, Akhurst RJ, Balmain A: Metastasis is driven by sequential elevation of H-ras and Smad2 levels. Nat Cell Biol 2002, 4:487-494.

34. Van Aarsen LA, Leone DR, Ho S, Dolinski BM, McCoon PE, LePage DJ, Kelly R, Heaney G, Rayhorn P, Reid C, Simon KJ, Horan GS, Tao N, Gardner HA, Skelly MM, Gown AM, Thomas GJ, Weinreb PH, Fawell SE, Violette SM: Antibody-mediated blockade of integrin alpha $v$ beta 6 inhibits tumor progression in vivo by a transforming growth factor-beta-regulated mechanism. Cancer Res 2008, 68:561-570.

35. Ikushima H, Miyazono K: Cellular context-dependent "colors" of transforming growth factor-b signaling. Cancer Sci 2010, 101:306-312.

36. Tian Y, Wu P, Luo AY, Xi L, Zhou JF, Ma D: Expression and significance of Smad2/3 and HPV16 E7 in cervical intraepithelial neoplasia and cervical carcinoma. Ai Zheng 2007, 26:967-971.

37. Kretzschmar M: Transforming growth factor-beta and breast cancer: Transforming growth factor-beta/SMAD signaling defects and cancer. Breast Cancer Res 2000, 2:107-115.

38. Kim YH, Lee HS, Lee HJ, Hur K, Kim WH, Bang YJ, Kim SJ, Lee KU, Choe KJ, Yang HK: Prognostic significance of the expression of Smad4 and Smad7 in human gastric carcinomas. Ann Oncol 2004, 15:574-580

39. Boulay JL, Mild G, Lowy A, Reuter J, Lagrange M, Terracciano L, Laffer U, Herrmann R, Rochlitz C: SMAD7 is a prognostic marker in patients with colorectal cancer. Int J Cancer 2003, 104:446-449.

40. Pring M, Prime S, Parkinson EK, Paterson I: Dysregulated TGF-beta1induced Smad signalling occurs as a result of defects in multiple components of the TGF-beta signalling pathway in human head and neck carcinoma cell lines. Int J Oncol 2006, 28:1279-1285.

\section{doi: 10.1186/1476-4598-9-106}

Cite this article as: Mangone et al., Smad2 and Smad6 as predictors of overall survival in oral squamous cell carcinoma patients Molecular Cancer 2010, 9:106

\section{Submit your next manuscript to BioMed Central} and take full advantage of:

- Convenient online submission

- Thorough peer review

- No space constraints or color figure charges

- Immediate publication on acceptance

- Inclusion in PubMed, CAS, Scopus and Google Scholar

- Research which is freely available for redistribution 